\title{
Innovative Thinking of E-commerce Development of Commercial Banks
}

\author{
Zhang Lianze ${ }^{1,2}$ \\ ${ }^{1)}$ Glorious Sun School of Business, Donghua University, Shanghai, China \\ ${ }^{2)}$ China CITIC Bank, Beijing, China
}

\begin{abstract}
The paper focused on the purpose and status of domestic commercial banks e-commerce; It proposed innovative ideas of relying on centralized procurement to expand e-commerce businesses and analyzed opportunities and challenges of the development of e-commerce through centralized procurement. The anchor considers that the model is a robust development road for commercial bank entering the field of electronic commerce and providing the Internet financial innovation services to SMEs.
\end{abstract}

Keywords - commercial bank, Internet financial, centralized procurement, e-commerce, SMEs

\section{商业银行发展电子商务的创新思考 \\ 张连泽 ${ }^{1,2}$ \\ 1) 东华大学旭日工商管理学院, 管理科学与工程专业博士生, 上海, 中国 \\ 2) 中信银行, 北京, 中国}

\begin{abstract}
摘 要 本文重点分析了国内商业银行电子商务的目的和状况; 提出了依托集中采购业务拓展电子商务的创新思路; 剖析了通过 集中采购发展电子商务的机遇与挑战。笔者认为这种模式是商业银行进军电子商务领域, 为中小型企业提供互联网金融创新服务的稳 健发展之路。
\end{abstract}

关键词＼cjkstart商业银行，互联网金融，集中采购，电子商务，中小企业

\section{1. 引言}

互联网金融是目前多手可热的话题。在互联网金融生 态圈中, 商业银行和电商企业是投入人力财力物力最多的 企业, 纷纷利用自身优势涉足电子商务新领域的业务创新。 依托集中采购发展电子商务是可以探索之路。

2013 年是互联网金融发展元年，互联网金融是 2013 年曝光率最高的热点之一, 互联网金融的话题采手可热。 有人认为互联网金融是网上理财, 有人说是 P2P 网贷, 还 有人说是电子商务, 众说纷纭。还有一种观点认为互联网 金融是电子商务的一部分, 学术界没有明确的定义, 监管 部门也没有给其清晰的边界。我认为互联网金融和电子商 务是互相融通的, 也是相互融合的, 目标均是通过互联网 推动金融和电子商务的发展, 不断提升客户体验和工作效 率, 经过市场充分竞争和检验后, 互联网、金融和电子商 务的发展必然趋于融合。本文重点思考商业银行推动电子 商务发展的创新方法和途径。

\section{2. 商业银行拓展电子商务的目的及状况}

商业银行是企业单位和政府融资的主要来源, 银行贷 款是获取有价资金的主要方式。近年来, 随着国内资本市 场的开放，影子银行和民间贷款的快速发展，新的资金获 取方式也在不断地涌现, 进而在一定程度上缓解了中小企 业融资难问题。国有商业银行正在通过电子商务解决部分 中小企业的融资问题。

目前, 我国电子商务模式按照交易对象主要涵盖了 $\mathrm{B} 2 \mathrm{~B}$ 电子商务、 $\mathrm{B} 2 \mathrm{C}$ 电子商务、 $\mathrm{C} 2 \mathrm{~B}$ 电子商务和 $\mathrm{C} 2 \mathrm{C}$ 电子 商务模式。尽管电子商务生态圈中的各类参与者关注热点 和重心还是部署在 B2C、C2B 和 C2C 等模式上, 但从国内 外学者对电子商务各种模式研究发现, B2B 电子商务可为 传统商业带来一场颠覆性的变革, B2B 电子商务必然是电 子商务发展的主流。其中 $\mathrm{B} 2 \mathrm{~B}$ 居于绝对主导地位, 也是我 国盈利状况最好的电子商务模式。B2B 无疑是整个电子商 务市场的中流砥柱。 
巴塞尔协议III要求对控制银行业的系统性风险、维护 金融系统稳定提出了更加严格的监管要求。再加上我国互 联网金融大环境下, 商业银行传统业务运营模式面临巨大 挑战, 商业银行思考必须转型, 商业银行在互联网金融发 展中拓展电子商务将是明智战略上的选择。

目前商业银行开展电子商务业务主要追求三个目标:

第一个目标是获取数据。银行做电子商务是想通过企 业线上的商务活动, 不断积累中小企业或个人的真实数据, 进而利用这些数据为企业客户和个人客户贷款类业务提供 可靠决策依据。银行通过做电子商务可以很好地缓解中小 企业经营数据缺失的问题。

第二个目标是增加中间业务收入。随着金融市场逐步 开放, 利率市场必将放开, 存贷差也将日趋收窄, 金融机 构将受到前所未有的挑战。面对这种环境, 商业银行必须 转型, 寻找新的业务增长点来弥补即将失去的政策保护红 利, 这就是增加中间业务收入。在互联网金融、大数据、 云计算、电子商务等各个方面和传统业务相结合, 电子商 务是商业银行尝试推动业务创新的主要方向之一。

第三个目标是通过提升核心竞争力提振股价。据业内 专家分析 2014 年 2 月 11-13 日中信、平安和民生等多家的 股价连续上扬, 甚至出现了多个涨停板, 均与互联网金融 的创新题材密切相关。

20 世纪末, 国内商业银行即纷纷布局了电子银行服务。 经过十多年的发展, 商业银行电子银行业务替代率平均水 平已超过 $70 \%$, 这表明传统银行业务的网络化已经达到较 高的水平。2005 年以来, 部分商业银行开始尝试建立自己 的电子商务平台, 探索互联网金融的电子商务业务创新, 并且取得了显著的成果。

\section{1 工商银行}

2014 年 1 月, 工商银行的“融 $\mathrm{e}$ 购”电子商务平台正式 上线运营。融 $\mathrm{e}$ 购商城以 $\mathrm{B} 2 \mathrm{C}$ 为主, 重点突出银行业支付 灵活、融资便捷的金融服务优势, 凸显“购物可贷款, 积分 能抵现, 品质有保障, 登录很便捷”的特点。工行“融 $\mathrm{e}$ 购” 平台坚持“名商、名品、名店”的定位, 以特色性、便利性、 专业性、安全性为原则, 有机整合客户与商户, 有机链接 支付与融资, 有机统一物流、资金流与信息流, 努力打造 客户喜爱的消费采购平台、商户倚重的销售推广平台以及 支付融资一体化的金融服务平台。上线仅仅两个月，该商 城就汇集了数码家电、汽车、金融产品、服装鞋帽、食品 饮料、珠宝礼品、交通旅游等 10 多个的行业数百个知名品 牌, 实时在线销售着近万件畅销商品。

\section{2 建设银行}

2010 年建设银行开始筹建自己电子商务平台“善融商 务”。因为运营成本“高”, 网站规模“大”, 商品品类“全”的 原因, 所以业内认为 “善融商务”走的是“高大全”路线。该 平台于 2011 年末正式上线投入运行。目前该平台目前主要 形成两个部分, 一个善融企业商城, 主打中小企业 B2B, 一个是善融个人商城, 主打中小企业售卖东西给普通消费 者的 B2C 模式。从商业模式上来看, 建设银行准备通过善 融商务复制出了一个“阿里巴巴”和一个“淘宝”。据资料显 示, 善融商务 2013 年全年交易量超过了 150 亿元, 较 2012 年增幅达 $328 \%$ 。平台上销售额最高的是手机、机动车、笔 记本/整机/平板和家具等品类的商品。从融资量上来看, 2013 年商户通过企业商城融资总额为 39 亿元, 假如按照 $1 \%$ 的存贷利息差计算, 可带来收入 3900 万元。

\section{3 民生银行}

2013 年 8 月 29 日, 民生电子商务有限责任公司在深 圳前海注册成立。民生电商的注册资本达到 30 亿, 电商平 台的名字为“合一行”。民生电商计划在北京、上海、深圳 三地布局。其中, 上海是总部、北京是技术研发基地、深 圳前海是跨境贸易出口。整体来看, 民生银行正式开始了 拓展电子商务业务的战略布局, 设想在互联网金融的电子 商务领域抢占先机。

\section{3. 依托集中采购发展电子商务的创新思路}

所谓商业银行集中采购, 是指商业银行通过招标、邀 请招标、竞争性谈判、询价、单一来源谈判等方式确定采 购对象, 集中统一用非个人资金以购买、租赁委托、雇佣 等方式获取大宗物品、工程。尽管商业银行集中采购已经 成为近来各家银行关注的热点话题之一, 但在这方面研究 还仅仅停留在集中采购业务上网的尝试研究, 将互联网金 融、电子商务、商业银行业务集一身应用于商业银行集中 采购管理研究还是一个空白。

随着我国商业银行从效益到规模经济的快速发展, 商 业银行的集中采购金额也呈快速上升的势态。针对我国商 业银行采购金额日益增加的情况, 建立商业银行电子集中 采购平台, 研究商业银行集中采购管理模式是大势所趋。 笔者认为商业银行可以分三步实施从内部单一客户采购 (简单的 B2B) 扩展到内部员工组成的特色客户加入形成 团购 (两个买方的 $\mathrm{B} 2 \mathrm{~B}$, 或者多个买方的 $\mathrm{C} 2 \mathrm{~B}$ ), 再到引入 商业银行的客户进入, 直至发展为成熟的电子商务服务平 台 (标准的 $\mathrm{B} 2 \mathrm{~B}, \mathrm{C} 2 \mathrm{~B}$ ), 进而实现商业银行进入电子商务 领域的目标, 使银行服务端口前移到客户的入口。 


\section{1 单一买方电子商务阶段}

这一阶段是商业银行从事电子商务的打基础阶段。重 点是做好拓展电子商务的发展规划, 其中包括产品体系、 业务结构、品牌策略和实施计划等。具体是将集中采购供 应商管理规范标准化, 引入供应商准入退出机制、分类等 级和评级管理等。实施采购计划管理既可以做好采购计划 安排, 又可以有效引导供应商产品高效供应, 提高效率, 降低成本。规范内部采购流程也是这一阶段必不可少的, 是实现集中采购内部管理线上化的必要环节。文档管理是 规范管理和防范风险的必要手段, 在符合电子签名法的情 况下, 实现电子化的基础环节。这个阶段构建初始的电子 商务平台, 买方只有一个商业银行, 线上商品控制在自身 生产经营性需求和非经营性需求范围, 商业银行是相对强 势的买方，对梳理供应商具有比较优势。

\section{2 银行内部员工团购电子商务阶段}

经过第一阶段的基础发展之后, 供应商管理已经规范 进入正轨, 集中采购商品过程中价格、质量和服务方面的 优势已经显现, 商业银行与供应商间的业务合作日趋默契。 供应商的商品供应能力远远超过了商业银行常规购买需 求, 双方有在产品数量、种类方面进一步拓展的愿望。这 时团购形式引入商业银行内部员工采购是一个最佳解决方 案。这个阶段中有三种模式可供选择, 一是员工整体以另 一客户的名义参加集中购买需要的商品 (即以商品为单位 与商业银行自身同类商品需求打包形成团购); 另一种员工 则是以另一个买方 $\mathrm{B}$ 的名义采用商业银行自身商品购买同 样的价格去采购需要的商品; 最后一种模式相对比较复杂, 即是参照商业银行 B2B 集中采购的商品价格, 内部员工通 过建成的电子商务平台线上采用所需的商品。这个阶段客 户从单一拓展到两个或多个内部客户, 探索 $\mathrm{C} 2 \mathrm{~B}$ 模式在 $\mathrm{B} 2 \mathrm{~B}$ 平台的拓展。

\section{3 市场化运作电子商务阶段}

这个阶段是在供应商数量、商品种类和交易频度方面 均已形成较大规模, 系统平台、运营机制和品牌建设已经 达到可以推向市场的程度。系统建设可以在解决安全机制 后拓展到外部公共网络的服务, 同步可以将内部用户迁移 或增加外部接入方式的服务。电子商务平台可以尝试市场 化的运营机制, 探索引入事业部、独立法人或委托外部运 营等方式实现电子商务平台的独立化运行。这时引入商业 银行拥有的客户群, 整合电子商务平台和电子银行的渠道 服务, 进一步可将商业银行的保理、现金管理、供应链融 资和网上理财等众多产品融合到电子商务业务中, 形成真
正商业银行电子商务一站式服务, 进而实现规模、效益、 品牌和竞争力等各个方面的突破。

这种模式具有与商业银行金融网络化联系紧密、与现 有常规业务结合程度较高、投入人力和资金成本低的特点, 而且是一条商业银行稳健发展电子商务之路。经过三个阶 段分步实施后, 商业银行将会构建起与商业银行自身其他 业务合作最紧密、产品体系合理、成效分布实现, 而且具 有市场竞争力的电子商务服务体系。初步设想构建的产品 体系架构图参见“集中采购---电子商务结构图”。

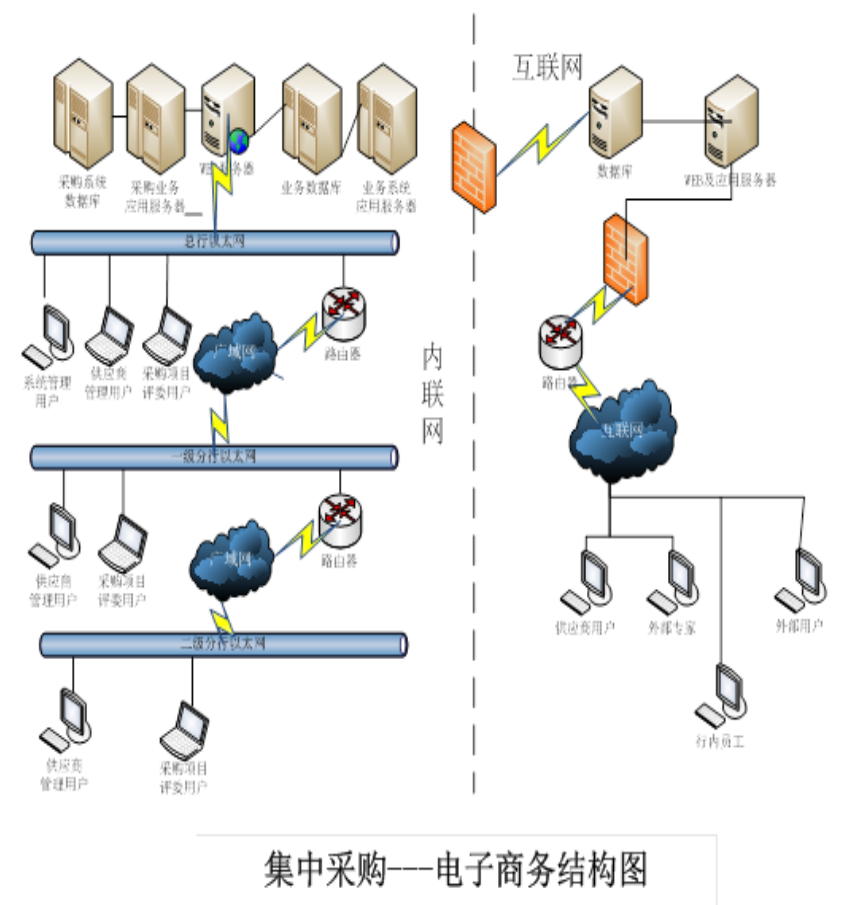

\section{4. 商业银行依托集中采购拓展电子商务服务的机遇 与挑战}

尽管我们相信商业银行依托集中采购业务分三个阶段 可以稳步进入电子商务领域, 但从 SWOT 分析角度, 仍然 有必要全面分析商业银行依托集中采购拓展电子商务的机 遇与挑战。

\section{Strength (优势)}

1、商业银行有充足的资金支持推动电子商务平台建设 和运营;

2、交易平台有足够的业务量支持和保障。据了解, 全 国性股份制商业银行每年采购金额至少在 30 亿元人民币 以上。随着业务增长, 采购量还会逐年增加;

3、有丰富的商品需求。商业银行用于经营性活动和非 经营性活动的采购需求非常旺盛。 
4、有扩展电子商务的资源。引入员工团购和银行客户 进入电子商务平台, 商业银行可以利用规模效应获取价格 方面、提升谈判地位、丰富商品以及售后服务等方面。

5、商业银行的信用可以吸引更多的供应商。银行是经 营信用的金融机构, 可以为电子商务业务提供信用保障。

\section{Weakness（劣势）}

1、银行自建电子商务平台缺乏有效风险控制手段。银 行自荐电子商务平台有一个问题是始终绕不开的, 那就是 如何确保运营电商平台产生的风险, 比如假冒伪劣产品、 消费纠纷等不会伤害银行自身的形象?

2、银行运营电子商务在体制上动力不足。银行保守的 行事作风, 银行电商必定存在行事保守, 竞争无力, 缺乏 狼性等特点。商业银行往往是以一个部门或一个条线的方 式运营管理电子商务平台, 这与互联网金融思维方式存在 不同步不协调的问题;

3、银行开展电子商务在监管方面模糊不清。从商业银 行法和监管法规角度看, 商业银行以控股或独立法人方式 运营一个企业（包括电子商务企业）存有争议;

4、开展电子商务只是银行业务的补充。从分析商业银 行从事电子商务的目的可以看出, 商业银行只是将电子商 务作为获取数据和中间收入的一个手段, 很难将其纳入到 发展战略的高度。

\section{Opportunity（机会）}

1、大数据时代来临, 商业银行可以通过拓展电子商务 业务获取除了常规资金信息以外有价值的数据;

2、通过电子商务活动, 可以增强现有客户的粘性。

3、通过采购活动, 可以扩大商业银行与供应商合作的 契机。

4、通过采购活动, 可以为电子商务平台与商业银行更 多业务合作的契机。

5、推动商业银行供应链金融的有序发展。

6、推动和保障商业银行集中采购商品的良性供应。

7、有效防范和规避电子商务活动中的风险。利用商业 银行具有严密的信用评估体系、严谨的风险控制机制和先 进的科技系统等, 使电子商务活动形成闭环, 从而有效降 低和控制电子商务所有节点中的风险。

\section{Threaten（威胁）}

1、来自电子商务公司业务快速增长的挑战。在互联网 金融热潮的推动下, 以淘宝、京东、腾讯和苏宁等代表的 企业纷纷涉足电子商务业务, 并获得市场和客户的认可;
2、来自第三方支付公司业务扩张的威胁。中国人民银 行近几年颁发了 250 多张第三方支付公司牌照, 对商业银 行支付结算和代收付等业务形成竞争, 进而开始进入电子 商务领域;

3、来自银行内部运作机制的威胁。商业银行转型方向 不明朗, 节奏不够迅速, 仍然保留在原有的运行机制上。

总之, 商业银行在互联网金融的热潮中, 不论是在产 品体系构建, 还是营销思路的转变均经历着来自多方的挑 战和考验。商业银行如何能在充分发挥自身优势的基础上, 稳健成体系的创新业务和拓展新领域, 是摆在所有商业银 行面前的难题。我想商业银行依托集中采购去拓展电子商 务将是一条可探索尝试的方向, 同时也希望在不久将来有 商业银行通过这条路径成功发展具有自身特色的电子商务 业务。

\section{参考文献(References)}

[1] Ma Weihua. Capital constraints and business transformation. Beijing: CITIC Publishing House, 2005.8.

[2] Yi Huiman. Motives, objectives and implementation approaches of transformation of China's commercial banks. Financial Forum, 2006(9).

[3] Sutton S G, Khazanchi D, Hampton C, et al. Risk analysis in extended enterprise environments: identification of critical risk factors in B2B e-commerce relationships. Journal of the Association for Information Systems, 2008, 9.

[4] Pathak J, Lind M R. An e-business audit service model in the B2B context. Information Systems Management, 2010, 27(2).

[5] Fu Cuixiao, Qin Min, Huang Lihua. The study on the transformation strategy of enterprise to the platform of B2B electronic commerce mode. Business Economics and Management, 2011, 1 (8).

[6] Wiersema F. The B2B Agenda: the current state of B2B marketing and a look ahead. Industrial Marketing Management, 2013.

[7] Wang Jiaying, Wang Juemin. The study of the development of commercial bank e-commerce platform. financial aspect, 2013 (6): 86-91.

[8] Yang Jing. Thinking on centralized procurement of commercial banks. Financial Times, 2011 (36): 132.

[9] Yi Na, Wu Wei. Centralized procurement of commercial banks under strategic sourcing. New Money, 2008 (6): 72-74.

[10] Liu Jian, Zhu Rui. Research on modes of commercial bank strategic alliance operation. Modern Finance, 2012 (8): 30-32. 